4 to scarlet fever, 3 to whooping-cough, and not one either to small-pox or diphtheria. Thus the deaths resulting from these principal zymotic diseases, which had been 78,48 , and 65 in the preceding three weeks, further rose again last week to 77 ; they were equal to an annual rate of 11.4 per 1000 , the rate from the same diseases being but $3: 3$ in London and 48 in Edinburgh. The fatal cases of diarrhoea, which had been 39,30 , and 31 in the previous three weeks, rose again last week to 36 . The deaths from measles, however, showed a decline of 6 from the number in the previous week. The 7 deaths from "fever" showed a further increase upon the numbers in recent weeks, while those from whooping-cough were less numerous. The deaths both of infants and of elderly persons showed a marked decline from the high numbers returned in the previous week. Six inquest cases and 2 deaths from violence were registered; and 53, or considerably more than onefourth, of the deaths occurred in public institutions. The causes of 28 , or nearly 15 per cent., of the deaths registered during the week were uncertified.

\section{THE SERVICES}

Deputy Surgeon-General R. W. Clifton has been appointed Principal Medical Officer to the Curragh Brigade.

ARMY Medical Staff.-Surgeon Richard Charles Kirby Laffan has been seconded for service under the Egyptian Government.

Militia Medical Department.-Surgeon-Major J. R. A. Douglas, 5th Battalion, the Royal Fusiliers (City of London Regiment), resigns his commission; also is permitted to retain his rank and to wear the prescribed uniform on his retirement.

ARTILLERY VoLUNTEERs.-1st Glamorgan: Philip Rhys Griffths, M.B., to be Acting Surgeon (dated Sept. 10th, 1887).

RIFLE VOLUNTEERS.-2nd Volunteer Battalion, the Worcestershire Regiment: Willism Leonard Braddon, M.B., to be Acting Surgeon (dated Sept. 10th, 1887).--1st Volunteer Battalion, the Northumberland Fusiliers : Acting Surgeon C. Farmer resigns his appointment (dated Sept. 10th, 1887).

ADMIRALTY.-In accordance with the provisions of Her Majesty's Order in Council of April 1st, 1881, Staff Surgeon James Robertson has been placed on the retired list of his rank (dated Sept. 2nd, 1887).

The following appointments have been made:-Surgeon Alfred E. Weightman, to the Garnet (dated Sept. 10th, 1887) Surgeon George T. Collingwood, to Chatham Hospital (dated Sept. 10th, 1887); and Surgeon James Crevie, to be Surgeon 8nd Agent at Belhelvie (dated Aug. 31st, 1887).

\section{Uorespondence.}

$$
\text { "Audi alteram partem." }
$$

\section{THE TREATMENT OF PERFORATING ULCER.} To the Editors of THE LANCET.

SIRs, -I have read with much interest the cases of perforating ulcer recorded by Mr. Bland Sutton and Mr. Pryce in THE LANCET of July 2nd, for I have continually to treat a number of cases of this troublesome complication in the Leper Asylum here. I must, however, comment on a point in treatment, which I am aware is not new, but which does not seem to be sufficiently recognised. I have before me notes of three cases in which I cut down upon and stretched the sciatic nerve for painful perforating ulcer. In the first case the ulcer healed and the pain vanished. In two months, however, it returned so severely that the patient begged for amputation. I then stretched the external popliteal and slit up a sinus in the sole, making a large $T$ incision. Since that date (five months ago) he has made no complaint. The Ulcer is not quite healed and seems inclined to remain stationary. In the second case the pain was relieved, the swelling of the foot diminished, and the ulcer lessened in size. In five months more the foot became very swollen and inflamed, the ulcer very painful, and dead hone was remored. He also begged for amputation. Instead of this, the foot was freely incised in various directions, and sloughs carefully removed as they formed. In a month the ulcer on the sole was nearly healed, the incisions were granulating well, and there was no pain except when he tried to walk on the foot. In the third case there was temporary relief; but the foot became gangrenous, and at the patient's own request the leg was amputated a month later. The posterior tibial nerve was greatly thickened, the fibres being separated by gelatinous-looking material. The stump was perfectly healed in two months more, and the patient was getting about with a wooden leg.

I could multiply examples, but these are enough for the present purpose. My experiences of nerve stretching are still accumulating, and are not yet ripe for publication; but this I feel justified in saying, as a result of observation so far, that amputation for perforating ulcer should never be thought of till nerve stretching and free incision of the ulcer have been thoroughly tried.

I am, Sirs, yours truly,

BEAVEN RAKE, M.D. Lond.,

Medical Superintendent of the Trinidad Leper Asylum .

August 13th, 1887.

\section{PAIN AND ITS INTERPRETATION.}

\section{To the Editors of THE LANCET.}

SIRs,-I have read with great interest the articles published in THe LanceT under the above heading. They have already called forth letters of protest, at which I am not surprised, containing as they do much that is debatable.

As a general proposition, it may safely be said that pain is of service to mankind. To this, I imagine, no one will demur. It is one of the solid foundations on which our treatment is based. Proofs of it are abundant. Take, for instance, an injured joint. A man gives his knee a violent wrench; the structures are severely strained; some of the ligaments are ruptured; and synovitis follows. The man has pain, which is increased on movement, and so instinctively the joint is kept fixed and is given rest. The surgeon. fixes the knee on a splint, absolute rest is maintained, but. still pain continues. At first the pain was useful, and amongst other things pointed out the treatment; but when rest is obtained, of what use is the pain?

In many and various other instances the utility of pain is clear; but to say, as was said by Mr. Gillies, that "pain comes at the right time," and "never comes where it can serve no good purpose," is palpably fallacious. Take the case of a woman with that truly terrible affliction, scirrhus of the mamma. It begins as an excessive epithelial growth, at first perhaps of only a very few cells. A small tumour is developed, and for weeks or months she may be completely unconscious of it. Now pain in her case, to be of good purpose, should be felt quite early in the course of the important change. What do we find? For months, may be, she is quite ignorant of the fact that she has within her the beginning of what will ultimately bo her end. The tumour growe, neighbouring structures become contaminated, and pain comes on and persists, which by the exhaustion it induces hastens on the inevitable. In this stage, of what service is her pain? The diagnosis is made, the disease is too far advanced for operation, the patient knows that she is beyond the reach of surgery, and so, tortured with pain night and day, she waits, and prays for a speedy release. And yet the writer stoically says, "Pain is merciful."

Further on he says: "Pain is in direct proportion to the powers of repair-that is, to the probability of recovery." So it appears that the woman who is the most affected with cancer and suffers the most pain is more likely to recover when operated on than the one who has the small, initial. and painless cancerous tumour! Is this the teaching of modern surgery? Is this the practice of its disciples-the writer of the articles amongst them? The one fact that stands out clearly in the statistics of the operations for cancer is that the sooner the patient is rid of the tumour the better will be the prospect; and could we but diagnose the affection in its painless state, when it first becomes: heterologous, and acted accordingly, the prognosis would be extremely favourable. This, unfortunately, we are unable to do.

The writer would have us believe" that the measure of pain which attends an injury or a disease is a prophecy in that same measure of recovery." If so, then the more acute and painful a pleuro-pneumonia, the more pain after a fractured rib the more pain after a ruptured bladder, the 
more acutely strangulated and powerful a hernia, the more excruciating the headache in meningitis, the greater are the prospects of recovery! Different temperaments do not enter into his calculations; it is one absolute rule- "the more pain, the more likely to recover." If he follows his own conclusion he will most assuredly be led into many a pitfall.

If pain be the unmixed blessing we are asked to believe it is, why do we in all cases endeavour to palliate it? Why does health suffer from its persistency? Why often when pain ceases does health improve? And why do we completely abolish it during the performance of operations? Pain is a universal human legacy. It is the penalty we pay for our high state of development. It is what generations of medical men in all climes have striven with all their strength and knowledge to lessen or to annul. We walk in their footsteps, but with more powerful weapons against the dread inheritance. Others will follow us, and so the warfare will ever continue.

I am, Sirs, yours faithfully, E. R. WILLTaMs, M.R.C.S.

Richmond Gardens, Forest Gate, H., Sept. 12th, 1887.

\section{To the Editors of THE LANCET.}

SIRs,-Relative to your annotation "What is Pain?" and also to the articles on the "Interpretation of Disease," may one inquire if it is not as absurd to speak of the "purpose of pain " as it would be to talk about the purpose of hæmorrhage from a severed vessel? In the latter case the function - it may be called-of conveyance is interfered with and blood flows out and is lost, but no one talks about the purpose of loss of blood. It is perceptible to our senses just as much as pain is, and is additionally perceptible to sight, and no doubt serves as a warning to us to take measures to check it; but would anyone therefore speak of the purpose of hamorrhage as "protective"? Yet you write-" the purpose of pain is doubtless protective." Hæmorrhage in general terms is a consequence-a sign - of failure, in greater or less degree, of a function of vascular tissue - viz, conveyance. So pain is a consequence, a sign of failure of function of nerve or other tissue; and, as a failure, as a defective performance, it has no more purpose than hæmorrhage or any other failure or deficiency has, "Purpose" is surely confined to normality, and when the natural conditions under which an organ or a tissue does its work are changed to the extent of causing, for example, hæmorrhage, or pain, or what not, is it not beside the question to talk of "purpose" in it all? All "purpose" was probably expended in providing for the normal working of parts. What "purpose" there may be in disease or its symptoms-e.g., pain, bæmorrhage, \&c.-is due to the persistence to the survival of some elements of normality in function, and it is a mistake to speak of the "purpose" of what is really the failure of purpose and nothing more. I am, Sirs, your obediently,

$$
\text { Sept. 1887. G. C. LIPPINCOTT, M.D., U.S. Navy. }
$$

\section{To the Editors of THE LANCET.}

SIRs,--It is in no contentious spirit I write you again on this most important question, but in the hope, as I have already expressed, that some good will come of it. Dr. Collins compels me to quote a sentence from my last paper: "Now, let me say that there are serious exceptions-apparent exceptions - to this law of pain." I leave him to judge whether I meant to cover cancer by that. I made the expression general for a purpose, and that purpose has been served so far well. I hoped to get men of greater knowledge and experience than I can justly claim to give the fulness of detail that I so clearly saw was at this very point necessary. Towards that Dr. Collins in his two letters has contributed nothing. When I said I did not understand his explanation, I did so honestly fearing that there might be something more in his theory than I could then see-something that his words failed to convey with sufficient clearness. But now that Dr. Campbell has put the matter in a very simple effective expression I am quite ready to accept it, and that entirely in favour of my view of pain, not against it. But let me indicate that the method or process of the evolution of pain is a question at every point quite distinct from the purpose of pain. It is with the meaning, the motive of pain, that I am concerned, not with the process of its evolution. Mr. St. Clair Buxton looks at the matter from the same point of view as Dr. Collins; but that "pain stands out simply as an evidence of evolution" is what I cannot aecept. Pain has some other and higher purpose than that.

I am not clear as to what Dr. Collins means in his reference to anæsthetics. The use of anæsthetics in surgical operations is clearly outside the question at issue. Their administration to suppress natural pain is not rarely a questionable proceeding; it is at best a temporary expedient. I tbink it was Lord Macaulay who said that the suppression of pain by opiates was like taking the warning rattle off the snake but leaving it in full possession of its fangs. I need not elucidate this truth to your readers; they are daily familiar with the fact. In the measure that we know the cause of pain and understand its meaning, I believe anæsthetics shall have more limited use.

There are several points in Dr. Campbell's excellent, thoughtful letter that I prefer not to deal with at present. If I am not mistaken, Dr. Campbell could put us much in his debt by answering his own questions. Would it be too much to ask him at convenience to do so?

Brockley, S.F.

$$
\text { I am, Sirs, your obedient servant, }
$$

H. Cameron Gillies.

\section{DEATH FROM CHLOROFORM. \\ To the Editors of THE LANCET.}

SIRS,-As it is important that a permanent record should be kept of all cases of death arising out of the administration of anæsthetics, I send you particulars of a death which recently occurred at the Chester General Infirmary-a short account of which has appeared in some of the daily papers.

On Aug. 16th last, a patient, W. L-, aged thirty, was admitted to the infirmary suffering from necrosis of a metacarpal bone, the result of an injury received five months previously. It being considered necessary that the piece of dead bone should be removed, Mr. Lees, house surgeon, on Aug. 18th, asked me to give chloroform for him whilst he performed the operation. The patient had no symptoms of cardiac disease, and both Mr. Lees and myself examined the pulse immediately before the operation, and found it regular and healthy. I administered the anæsthetic on lint, the patient coming very rapidly under its influence (less than three minutes being occupied in obtaining this result), and not more than two drachms of chloroform being used altogether. Mr. Lees commenced the operation, and in a few seconds it was noticed that the pulse became very feeble and flickering and the respiration shallow. Almost immediately after this both pulse and respiration stopped Artificial respiration by Silvester's method was at once set up, hypodermic injections of ether given, nitrite of amyl sprinkled on lint placed over the nostrils, mustard applied to the heart, and an enema of brandy-and-water administered. Attempts to restore the patient were kept up for more than an hour, when the case was abandoned as hopeless. At the first symptoms of syncope, Dr. Stolterforth, one of the honorary physicians, was sent for, and was present while the efforts at resuscitation were being carried out.

A post-mortem examination was made on the following day by Mr. Lees. The right auricle was found very much distended with blood; all the val ves of the heart were healthy but its muscular substance was brown, and the walls thin and fatty (at the apex of the left ventricle the muscle was not more than one-eighth of an inch in thickness). Under the microscope many of the muscular fibres showed a central deposit of oily material. There were also some pleuritic adhesions.

At an adjourned inquest held on Aug. 26th, the coroner, after hearing the evidence, said " the jury could have little doubt that the deceased came by his death accidentally while under chloroform properly administered for the purposes of an operation. The state of the man's heart was not discoverable at the time of the operation, so not the slightest blame attached to the doctors." The jury expressed concurrence with the coroner and returned a verdict to that effect. I am, Sirs, your obedient servant,

Sept. Sth, 1837. ALFRED MTA Visiting Surgeon, Chester Infirmarr. 